\title{
Monitoring pumping station performance for maintenance optimisation
}

\author{
O.J. Tarrant ${ }^{1}$, K. Solts ${ }^{1, a}$, S. Carman ${ }^{1}$ and Y.Ugradar ${ }^{1}$ \\ ${ }^{1}$ Environment Agency, Bristol, England
}

\begin{abstract}
This paper describes the ambition of the Environment Agency to develop and trial predictive condition-based monitoring systems for its mechanical and electrical flood risk management equipment. The aims, objective and research methods for this project are described. The challenge of developing any predictive capability for flood risk management assets which, typically have a low frequency of operation and therefore a paucity of data, is discussed. Some practical suggestions to overcome this specific challenge are presented.
\end{abstract}

\section{Introduction}

This paper describes the ambition of the Environment Agency to develop a new condition-based monitoring system (CBMS) for their flood defence assets. A Research and Development (R\&D) project has been initiated to develop a proof-of-concept CBMS system using existing and novel sensing instruments allied with predictive analytical techniques.

The proof-of-concept system will be progressed to a stage of trial application, where it will be deployed on two different Environment Agency assets as a pilot trial. Willop and Greatstone pumping stations, located on the South East Coast of Kent (see figure 1), have been identified for this pilot as both assets are typically representative of our pumping station portfolio.

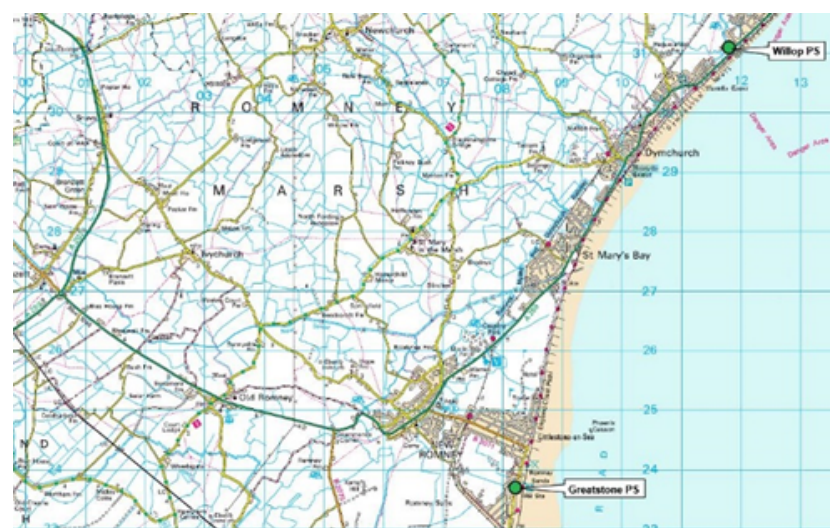

Figure 1: Location of Pumping Stations. Background map CC Crown Copyright and database rights 2017 Ordnance Survey

Whilst it is too early in the project to present results, this paper aims to highlight some of the important research challenges this work will be tackling. In particular, the project is anticipating the need to develop practical strategies and novel methods for sensor array design and robust predictive analytics that will operate in an environment that is data-poor with low equipment utilisation.

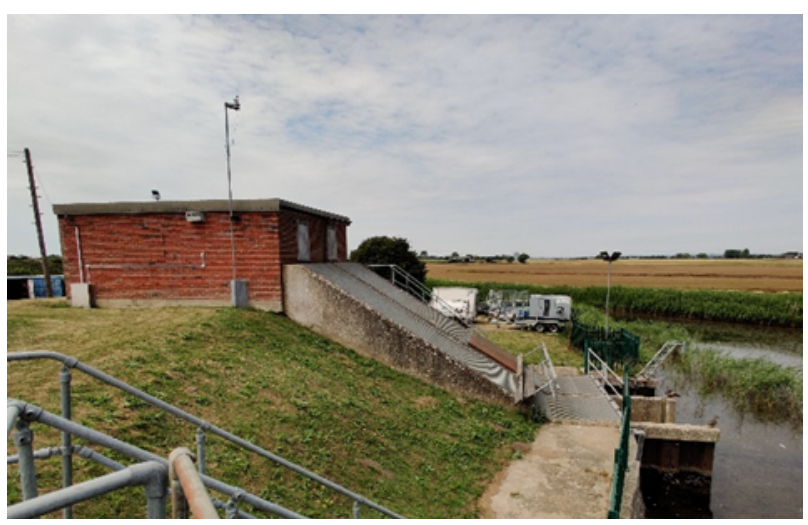

Figure 2: Photo of Willop Pumping Station

\section{Background}

\subsection{Strategic context}

The Environment Agency has set out in its asset management strategy (Environment Agency, 2017) the ambition to modernise its approach to Flood and Coastal Risk Management (FCRM) asset management and to be an industry - leading Asset Management (AM) organisation. The AM Strategy sets out further strategic objectives and outcomes for the period 2017-2022.

Among them are objectives to improve efficiency in maintenance delivery by $10 \%$, and to create better quality data and information. Allied to this is the target to achieve net zero carbon emissions by 2030 .

In England, there are over $£ 42 \mathrm{bn}$ of flood risk management assets protecting people, property and infrastructure from flooding. The Environment Agency

\footnotetext{
a Corresponding author: keith.solts@environment-agency.gov.uk
}

DOI 10.3311/FLOODRisk2020.14.1 
owns and maintains a significant proportion of these assets with an approximate value of $£ 26$ bn and has a strategic oversight for the remaining £16bn (Environment Agency, 2017). A significant proportion of the value of this infrastructure is attributable to Mechanical, Electrical, Instrumentation, Automation and Control (MEICA) equipment in flood risk systems.

The Environment Agency spends around $£ 12 \mathrm{~m}$ annually on the maintenance of MEICA equipment. From analysis of the computerised maintenance management system (CMMS) it has been seen that the Environment Agency currently experiences around 1200 breakdowns of MEICA equipment each year, rendering it redundant until repair. Associated with each of these equipment failures are costs of mobilising repair engineers (often out of hours) and cost of replacement components. There are of course, also, reputational risks and the risk that homes, businesses and lives could be disrupted if failure of equipment leads to flooding.

The Environment Agency is therefore exploring the opportunities available with new sensing technology and predictive analytics to help ensure maintenance budgets are spent effectively and efficiently and costly failures are avoided. The ultimate aim is to improve the overall reliability of the MEICA equipment portfolio, so the risk of flooding to people and their property is reduced.

\subsection{Current maintenance philosophies}

Maintenance of electro-mechanical equipment, such as the pumps in a pumping station, has traditionally taken place over set time periods as per the maintenance models set out by Barlow and Hunter (1960). This planned preventative maintenance philosophy (PPM) seeks to replace or repair components at set time intervals before a failure occurs. This maintenance regime has been adopted to ensure a high degree of 'on-demand reliability' (ODR) and makes resource planning far easier. In lower-risk locations, a PPM philosophy cannot be economically justified, in such cases, equipment is simply replaced either when it starts to show signs of imminent failure or has failed.

It has been demonstrated that neither of these maintenance philosophies deliver an optimum balance between risk of failure and cost of maintenance during operating life (e.g. Liu, Makis and Jardine, 1995; Nguyen and Murthy, 1981). PPM can result in costly maintenance programmes and equipment could be replaced with considerable operating life remaining or when relatively simple repairs could usefully extend operating time. Conversely, replacing equipment as the tell-tale signs of failure become visible can mean that the deterioration processes have reached the 'point of no return', it also makes resource planning difficult to predict and demands a highly flexible reactive maintenance resource. Routine maintenance and repair become ineffective and the only option is complete refurbishment or replacement.

\subsection{Sensing and predictive analytics}

Sensing instruments now exist that have been designed to collect data from equipment across a range of key performance variables such as vibration (Bindu and Thomas, 2014; Wang et al., 2018; Xu et al., 2018); temperature (Antunes et al., 2012) and many other variables that include but are not limited to:

- Current (Amps)

- Noise

- Flow

- Pressure

- Level

- Temperature

Data gathered from sensors arrays, together with analytical tools can provide complex views of network asset performance (Dadashi et al., 2014). Data analysis can provide valuable insight into the development of anomalies that indicate the onset of failure. Similarly, gradual deviations away from mean operating values revealed by sensing instruments, and subsequent signal processing, can indicate the degradation of parts. Analysing this data can improve decision making by, predicting when routine maintenance is required; preventing unexpected and expensive equipment failure; and, helping to optimise operations as well as maintenance, refurbishment and replacement activities. Kajko-Mattsson et al. (2010) describe the ideal management situation as, not just an awareness of where an asset has failed, but a clear picture of future states of degradation. The aspiration is to achieve predictive maintenance scheduling, with the twin benefits of identifying asset degradation before actual failure, and to allow planning of maintenance and renewals to be responsive to the actual state of the equipment, rather than driven by a fixed schedule (McDonnell et al., 2018). We need to ensure that the analysis of the data gives us triggers with enough lead time to be useful, and not generate false positives.

\section{The rationale for a pro-active approach to maintenance}

It has been estimated that by adopting a pro-active approach via condition-based monitoring to MEICA equipment maintenance could unlock a significant operational maintenance efficiency. This is the real motivator to ensure we overcome the challenges associated with the adoption of a predictive maintenance philosophy. Of the $£ 24 \mathrm{~m}$ average MEICA maintenance allocation a significant proportion is spent on motor-driven assets.

The case for change becomes more compelling when the potential for carbon savings are considered. The 340 pumping stations the Environment Agency operates contribute to over $30 \%$ of the total of the Environment Agency's operational carbon emissions. Small efficiencies across all pumping stations operations stand to yield large carbon savings when viewed at an organisational level. When the pumping stations that are operated by the other risk management authorities (RMAs) such as the Internal Drainage Boards are considered too, then there is the real opportunity to ensure greater carbon efficiency across 
flood and water level management as a whole. This work could make a significant contribution to our organisation's e-mission targets to reduce our carbon footprint to net zero.

\section{Objective and research methods}

The aim of this research project is to enable the uptake of new sensing technologies and predictive analytical techniques, so proactive maintenance strategies can be developed. The objectives for this project can be divided into four stages:

1. Review and proof-of-concept of CBMS.

2.Proto-type design and specification of CBMS.

3. Deployment and pilot testing of proto-type.

4. Development of deployment strategy.

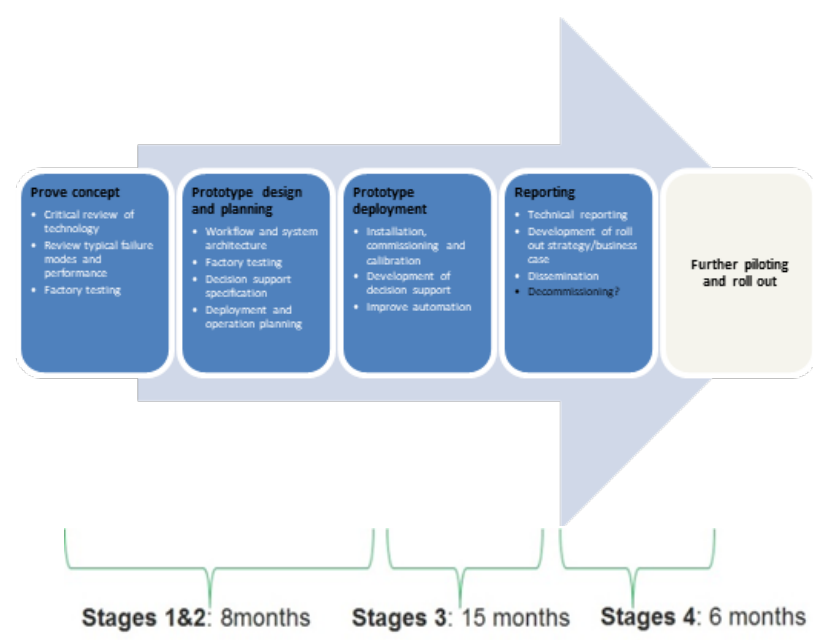

Figure 3: Stages of programme and key tasks

The methodology for the development of the proof-ofconcept CBMS system (stage 1) is expanded further below.

\section{Methods to develop proof-of-concept}

Work on the project commenced in January 2020. The first task is to review the suitability of sensors which are either already established or are emerging on to the market place. A short-list of potential sensor types will be compiled for monitoring the performance of various equipment. The technical review will be completed by engaging with original equipment manufacturers of the sensors to understand maturity, future potential and value. This task will also review installation implications to ensure that all proposed solutions are suitable to retrofit to the agreed operational setting of the pilot sites.

To guide the design and specification of the CBMS a full Failure Mode Effect and Criticality Analysis (FMECA) will be carried out in the first stage to identify key vulnerabilities and aid us in understanding the critical failure modes that would affect the overall functionality of the pumping station. Historical failure data will be used to understand how equipment in the pumping station has previously failed and how frequently. Using the FMECA process, each plant item will be assessed against various failures modes (for example pump electrical failure). Each failure is then assigned a risk score on the frequency of the failure event, the likelihood of detecting and reacting to the failure and the consequences of that failure occurring. See Figure 4.

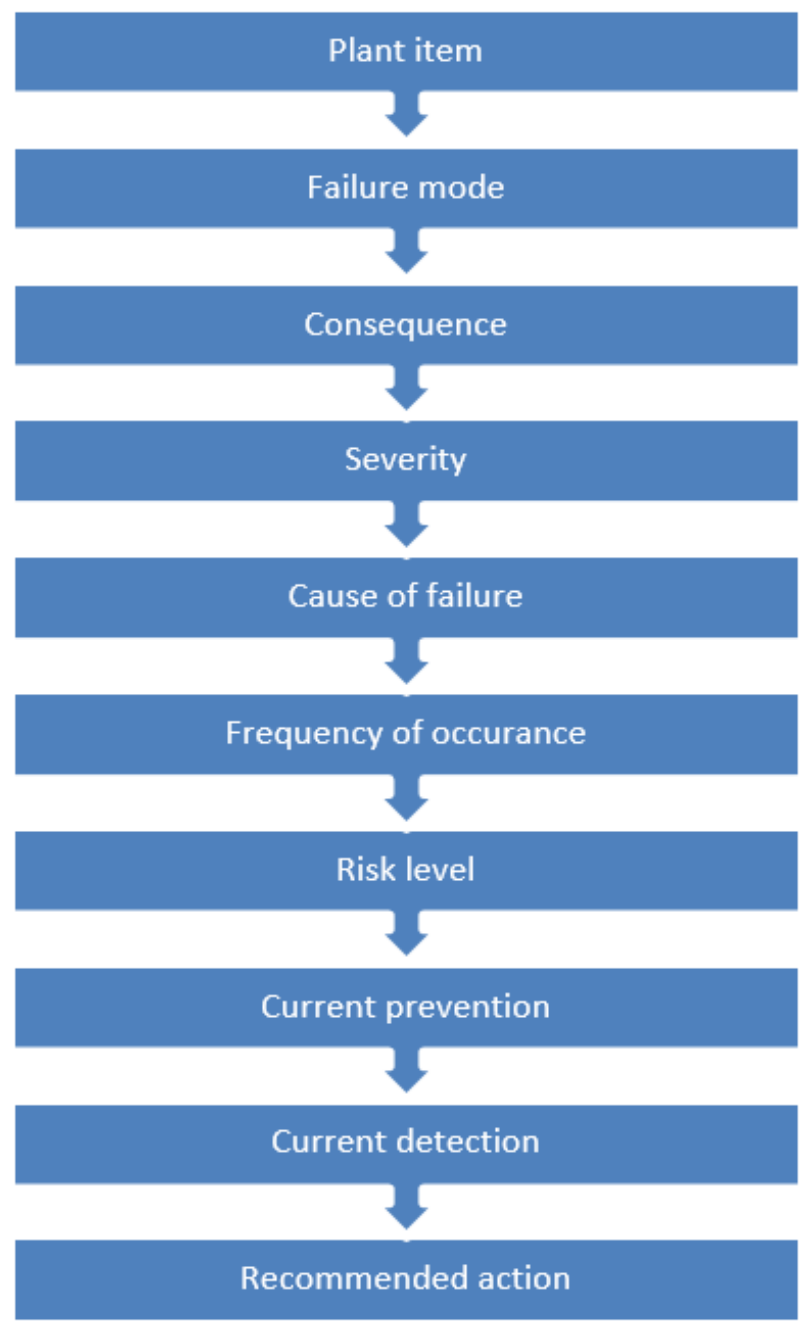

Figure 4: Process for Failure Mode, Effect and Consequence Analysis (FMECA)

The results of the FMECA will then be used to prioritise the design of the CBMS system. The FMECA analysis will feed into the sensor selection process to ensure that the most critical pieces of equipment are monitored and the right performance variables relating to failure modes are being diagnosed and measured.

Once a concept CBMS has been developed, factory testing will be undertaken. The FMECA will again be used to help specify the range of testing to be carried out. It is anticipated that a hybrid approach when both synthetic and physical stimuli will be used to demonstrate the system's ability to gather and retrieve data via remote connectivity. Similarly, both physical and simulated data will be used to develop and demonstrate the predictive analytics. At this point in the project, we anticipate that the analytics will be developed using proxy failure mode signatures. These proxies will be developed based on the limited historical failure data supplemented with expert judgement so realistic failure signatures are created. Models can then be trained against these failure signatures, so they can observe 
and predict them using real-time data supplied from the sensor array.

Signal processes techniques such as those described by Tavner, (2008) will then be applied to the data from the sensor array to boost the indicators of imminent failure. The analytics will also look for the subtler signs of degradation. New techniques will need to be developed to smooth signals, by filtering out background noise and normalising for changes in operational state over time. Minor inflections in the signals are likely to be indicative of emerging inefficiencies and signs of equipment wear.

Prior to deployment to site, the CBMS will need to go through a rigours security penetration test. Once this is complete the system will be installed and will undergo a 3month commissioning phase. If successful we will then commence with the full 12-month field trial.

\section{The challenge of low utilisation}

The deployment of sensing systems allied with predictive data analytical techniques is now becoming increasingly routine in many settings such as infrastructure asset management (Thaduri, et al, 2015), manufacturing (Lee et al, 2016), mineral extraction (Gupta et al, 2016). With the advent of Internet-of-Things (IoT) and smart, predictive analytics technologies, companies have been building a networked data-rich environment. Rapid sampling during continuous operational periods can quickly yield large amounts of data about the performance of critical components. Hence, frequently the term 'Big data' is often associated with predictive analytics (e.g. Gandomi and Haider, 2015; Waller and Fawcett, 2013)

The key challenge for us to effectively manage a large portfolio of flood defence infrastructure is the lack of useful data! Floods by definition are rare events; therefore, flood risk management infrastructure is used relatively infrequently and only for relatively short periods. This paucity of data associated with the use of plant and equipment under load makes it difficult to predict future performance. The collection of detailed and dense data during real operations is critical if we are to realise our ambition of a pro-active maintenance strategy.

There are some measures that can be taken to generate more data. These include exercising equipment such as pumps and their motors with soft starting techniques (i.e. starting motor but not engaging the drive to the pump impellors). However, there are also practical challenges and limitations with such strategies. For instance, pump exercising is often kept to a minimum as it can stir up sediments in the watercourse. This in turn can lead to low levels of dissolved oxygen and potential fish kills. Soft starting a motor only provides an indication of its performance as the motor does not experience any loading.

Another strategy to enrich equipment data, is to collect historical performance data from similar equipment types across the asset portfolio. Again, this comes with the difficulties of correcting for the difference in operational regimes and other variables.

Novel sensors and techniques may offer a solution. For example, techniques more often used in the field of structural health monitoring could offer some insight into the possible performance of important components. For example, Mba (2006) reviews the potential of Acoustic Emission Technology to the condition monitoring of rotating machinery.

If this work is to be successful it is likely that all these strategies will have to be employed. Data will have to be mined from unstructured sources and integrated with those collected from the sensing instruments. Pragmatic solutions will have to be found to increase utilisation without having negative impacts on the environment and carbon emissions.

\section{Conclusions}

The Environment Agency has a contract in place to undertake innovative research to develop a CBMS system for its MEICA equipment portfolio. Whilst other infrastructure owning organisations have been highly active in this area and have relatively mature equipment condition monitoring systems, the specific challenge of low utilisation of equipment has to date hampered flood defence managers from adopting similar asset management approaches.

This research project will look to tackle this challenge head on. The research team are in discussions with internal departments to implement pragmatic changes to existing operational philosophies to yield large amounts of performance data allied with the new advances in predictive analytical techniques and implementation of sensor monitoring technologies.

\section{Acknowledgements}

The work reported was funded by the Joint Environment Agency, Defra, Welsh Government and Natural Resources Wales Flood and Coastal Risk Management R\&D Programme.

\section{References}

1. Antunes, P.F.C., Marques, C.A., Varum, H. and Andre, P.S. (2012) Biaxial Optical Accelerometer and High-Angle Inclinometer with Temperature and Cross-Axis Insensitivity. IEEE Sensors Journal [online]. 12 (7), pp. 2399-2406. Available from: http://ieeexplore.ieee.org/document/6178265/doi:10. 1109/JSEN.2012.2190763 [Accessed 25 January 2019].

2. Barlow, R. and Hunter, L. (1960) Optimum Preventive Maintenance Policies. Operations Research [online]. 8 (1), pp. 90-100. Available from: http://pubsonline.informs.org/doi/abs/10.1287/opre.8 .1 .90 doi:10.1287/opre.8.1.90 [Accessed 25 January 2019].

3. Bindu, S. and Thomas, V. V (2014) Diagnoses of internal faults of three phase squirrel cage induction motor - A review. In: 2014 International Conference on Advances in Energy Conversion Technologies (ICAECT) [online]. January 2014 (no place) IEEE. pp. 48-54.

Available from: 
http://ieeexplore.ieee.org/document/6757060/doi:10. 1109/ICAECT.2014.6757060 [Accessed 25 January 2019].

4. Dadashi, N., Wilson, J.R., Golightly, D. and Sharples, S. (2014) A framework to support human factors of automation in railway intelligent infrastructure. Ergonomics [online]. 57 (3), pp. 387-402. Available from:

http://www.tandfonline.com/doi/abs/10.1080/001401 39.2014.893026doi:10.1080/00140139.2014.893026 [Accessed 25 January 2019].

5. Environment Agency (2017) Modernising Asset Management: Asset Management Strategy 20172022. Environment Agency. Bristol.

6. Gandomi, A. and Haider, M. (2015) Beyond the hype: Big data concepts, methods, and analytics. International Journal of Information Management [online]. 35 (2), pp. 137-144. Available from: https://www.sciencedirect.com/science/article/pii/S0 268401214001066?via\%3Dihubdoi:10.1016/J.IJINF OMGT.2014.10.007 [Accessed 25 January 2019].

7. Gupta, S., Saputelli, L. and Nikolaou, M. (2016) Applying Big Data Analytics to Detect, Diagnose, and Prevent Impending Failures in Electric Submersible Pumps. In: SPE Annual Technical Conference and Exhibition [online]. 26 September 2016 (no place) Society of Petroleum Engineers. Available from: http://www.onepetro.org/doi/10.2118/181510MSdoi:10.2118/181510-MS [Accessed 25 January 2019].

8. Lee, J., Bagheri, B. and Jin, C. (2016) Introduction to cyber manufacturing. Manufacturing Letters [online]. 8 pp. 11-15. Available from: https://www.sciencedirect.com/science/article/pii/S2 213846316300049?via\%3Dihubdoi:10.1016/J.MFG LET.2016.05.002 [Accessed 25 January 2019].

9. Liu, X.-G., Makis, V. and Jardine, A.K.S. (1995) A replacement model with overhauls and repairs. Naval Research Logistics [online]. 42 (7), pp. 1063-1079. Available from: http://doi.wiley.com/10.1002/1520$6750 \% 28199510 \% 2942 \% 3 \mathrm{~A} 7 \% 3 \mathrm{C} 1063 \% 3 \mathrm{~A} \% 3 \mathrm{AAI}$ D-NAV3220420706\%3E3.0.CO\%3B2-

3doi:10.1002/1520-6750(199510)42:7<1063: AIDNAV3220420706 >3.0.CO;2-3 [Accessed 25 January 2019].

10. Mba, D. (2006) Development of Acoustic Emission Technology for Condition Monitoring and Diagnosis of Rotating Machines: Bearings, Pumps, Gearboxes, Engines, and Rotating Structures. The Shock and Vibration Digest [online]. 38 (1), pp. 3-16. Available from:

http://svd.sagepub.com/cgi/doi/10.1177/0583102405 059054doi:10.1177/0583102405059054 [Accessed 25 January 2019].

11. McDonnell, D., Balfe, N., Pratto, L. and O’Donnell, G.E. (2018) Predicting the unpredictable: Consideration of human and organisational factors in maintenance prognostics. Journal of Loss Prevention in the Process Industries [online]. 54 pp. 131-145. Available from: https://www.sciencedirect.com/science/article/abs/pii
/S0950423016304107doi:10.1016/J.JLP.2018.03.008 [Accessed 25 January 2019].

12. Molecular Diversity Preservation International., J., Wei, L., Li, R., Liu, Q. and Yu, L. (2000) Sensors. [online]. (no place) Molecular Diversity Preservation International (MDPI). [Accessed 25 January 2019].

13. Nguyen, D.G. and Murthy, D.N.P. (1981) Optimal Preventive Maintenance Policies for Repairable Systems. Operations Research [online]. 29 (6), pp. 1181-1194. Available from: http://pubsonline.informs.org/doi/abs/10.1287/opre.2 9.6.1181doi:10.1287/opre.29.6.1181 [Accessed 25 January 2019].

14. Tavner, P.J. (2008) Review of condition monitoring of rotating electrical machines. IET Electric Power Applications [online]. 2 (4), pp. 215. Available from: https://digital-

library.theiet.org/content/journals/10.1049/ietepa_20070280doi:10.1049/iet-epa:20070280

[Accessed 25 January 2019].

15. Thaduri, A., Galar, D. and Kumar, U. (2015) Railway Assets: A Potential Domain for Big Data Analytics. Procedia Computer Science [online]. 53 pp. 457-467. Available from: https://www.sciencedirect.com/science/article/pii/S1 877050915018268doi:10.1016/J.PROCS.2015.07.32 3 [Accessed 25 January 2019].

16. Waller, M.A. and Fawcett, S.E. (2013) Data Science, Predictive Analytics, and Big Data: A Revolution That Will Transform Supply Chain Design and Management. Journal of Business Logistics [online]. 34 (2), pp. 77-84. Available from: http://doi.wiley.com/10.1111/jbl.12010doi:10.1111/j bl.12010 [Accessed 25 January 2019].

17. Wang, J., Wei, L., Li, R., Liu, Q., Yu, L., Wang, J., Wei, L., Li, R., Liu, Q. and Yu, L. (2018) A Fiber Bragg Grating Based Torsional Vibration Sensor for Rotating Machinery. Sensors [online]. 18 (8), pp. 2669. Available from: http://www.mdpi.com/14248220/18/8/2669doi:10.3390/s18082669 [Accessed 25 January 2019].

18. Xu, S., Xing, F., Wang, R., Li, W., Wang, Y. and Wang, X. (2018) Vibration sensor for the health monitoring of the large rotating machinery: review and outlook. Sensor Review [online]. 38 (1), pp. 4464. Available from: http://www.emeraldinsight.com/doi/10.1108/SR-032017-0049doi:10.1108/SR-03-2017-0049 [Accessed 25 January 2019]. 